\title{
Library Homepage Design at Medium-Sized Institutions
}

\author{
Scott L. Jones \\ Dean, School of Humanities and Social Sciences \\ Indiana University Kokomo \\ 2300 S Washington St \\ P.O. Box 9003 \\ Kokomo, IN 46904-9003 \\ scotjone@iuk.edu
}

\author{
Angie Thorpe \\ Digital User Experience Librarian \\ Indiana University Kokomo \\ 2300 S Washington St \\ P.O. Box 9003 \\ Kokomo, IN 46904-9003 \\ atthorpe@iuk.edu
}

Scott L. Jones is the contact author. Contact him at scotjone@iuk.edu

\begin{abstract}
About the Authors
Scott L. Jones received his PhD from Purdue University in 2002. His interests are in general Web design, homepage design, and social media. Dr. Jones has published in refereed journals in library science and communication, and he teaches in the new media program he founded at Indiana University Kokomo’s School of Humanities and Social Sciences. He can be contacted at scotjone@iuk.edu.
\end{abstract}


Angie Thorpe received her MLS from Indiana University and her BA in English from the University of Wisconsin-Madison. Her research interests include discovery services, the marketing of e-resources, and using data to make collection and content decisions. She currently serves at the Digital User Experience Librarian at Indiana University Kokomo. She can be contacted at atthorpe@iuk.edu. 


\title{
Library Home Page Design Practices at Medium-Sized Institutions
}

\begin{abstract}
This study sought to describe and analyze the home pages of academic library Web sites at 313 mediumsized bachelor's and master's general institutions. The authors evaluated an unprecedented number of library home pages for the presence of 118 design elements and reported common and uncommon design practices at these libraries. They found 21 elements present on at least half of the home pages studied. Seven of these occurred on at least 80 percent of the pages studied: links to the university home page, library hours, images, portals by subject or links to subject guides, links to interlibrary loan services, "about" sections, catalog searches, and library instruction tutorials. This study serves as a baseline for the current practices of home page design for a large population of libraries. The results of this survey indicate trends and common design elements for library Web site design and show which elements Web designers and librarians at medium-sized libraries should consider including on their Web pages. Findings are compared with a similar study conducted in 2010, and this study in turn may provide a comparison point for future research. The study also reports characteristics of the implementation of discovery services for this population of libraries in unprecedented detail and provides descriptive information about home page links to social media sites and mobile applications.
\end{abstract}

\section{Keywords}

World Wide Web, Web sites, University libraries, academic libraries, home page design, discovery services, library websites, design elements, social media 


\section{Introduction}

Students increasingly rely on library Web services to fulfill part of their academic library needs. The academic library home page serves as one access portal to many services that academic libraries provide. Yet as Web technologies rapidly change, studies of academic library home pages struggle to keep pace. While usability and user log studies can yield valuable data to drive design decisions for individual libraries, the wide variety of design choices preclude testing all design alternatives. As Scott L. Jones and Kirsten Leonard (2011) noted, one valuable approach to researching library home page design is to take a wisdom-of-crowds approach and analyze the design characteristics of a large number of library home pages.

The following study investigates the frequency of certain design and content choices for academic libraries at medium-sized, Baccalaureate Colleges-General and Master's Colleges and Universities I, using the Carnegie classification for a full-time equivalent population of 3,000-9,999 students. Web design at institutions in this study has been studied much less frequently than it has at larger institutions, and no in-depth studies of library home pages from this population have been conducted since Bradley P. Tolppanen et al. (2005) gathered their data in 2003. General Web and library Web design practices have changed since then, and the following study details current common practices among medium-sized libraries, providing valuable data and advice for those tasked with developing home pages for libraries of all sizes. Compared to larger or smaller libraries, the population of medium-sized libraries may have some distinctive research needs. This study will present data on the current attributes and design choices of medium-sized academic libraries to determine the standards of practice. The subsequent analysis will assist medium-sized libraries in making design decisions. Findings may also be used to explore how the Web design of medium-sized academic libraries compares to that of smaller and larger academic libraries, or as a basis for later historical comparison.

\section{Literature review}


There have been many articles studying library Web site design using a variety of methodologies. These have included case studies of implementing a site design or feature (Ganster and Schumacher 2009; Moore and Greene 2012), as well as usability testing of specific components, such as catalog systems (Emanuel 2011) and discovery tools (Majors 2012), or lists of electronic resources (Fry and Rich 2011). Others have studied larger issues of usability (Swanson and Green 2011; Tidal 2012).

Among the various ways to study Web sites (e.g. questionnaires, usability tests, and focus groups), one method is to examine multiple library Web sites to determine common practices. Yong-Mi Kim (2011) argued that library Web design should involve not solely usability testing but also the review of other library sites as well. Employing content analysis to study a large number of Web sites to determine Web design best practices is well-established. Outside of library design, this method has been used in many studies, including Jakob Nielsen and Marie Tahir's (2001) study of home pages, Scott L. Jones and Diana DeGrow's (2011) study of Fortune 500 home pages, and Scott L. Jones's study of state portal and agency home pages (2012).

This method has also been used to study library home page design in a variety of ways. Scott L. Jones and Kirsten Leonard (2011) designated four categories of studies examining site designs of populations of libraries. The first category was "studies using general Web design principles to examine home page or site designs in a population of libraries” (25). As Barbara A. Blummer (2007) noted, these have been infrequently conducted. Examples of such studies include those by Mark Stover and Steven D. Zink (1996), David King (1998), and Pamela Harpel-Burke (2005). The second category consisted of studies focusing on “one or more closely related design or content elements” (Jones and Leonard 2011, 25). Examples of this research category included Sarah C. Williams’s (2010) analysis of the use of federated search by Association of Research Libraries (ARL) members and Hannah G. Rempel’s (2010) review of links and programming content for graduate students on ARL and Oregon academic library Web sites. The third category is broader, examining "a population of libraries for a variety of content and design issues largely specific to academic libraries” (Jones and Leonard 2011, 26). This category includes Brian Detlor and Vivian Lewis’ (2006) analysis of ARL library Web site design. The fourth category 
“focuses on studying a population of libraries for a large number of design and content elements” (Jones and Leonard 2011, p. 26). An example of this was Noa Aharony’s (2012) examination of 42 content items on the Web sites of 31 Association of College and Research Libraries (ACRL) institutions with accredited library and information science schools.

It is possible that libraries of different sizes have different needs, as well as different levels of resources for producing Web sites. While we do not know the resources for libraries of every size, Kneip (2007) surveyed Webmasters of medium-sized academic libraries, and his results suggest that such libraries put limited resources into their Web sites; the Webmasters reported that they devoted less than ten hours a week to Web design and possessed limited formal training in Web design, particularly in more advanced Web technologies. Because of possible differences in resources among libraries of different sizes, researchers often study populations of university libraries of a specific size; thus, academic library studies can also be categorized by the size of the university housing the library. While many studies focused on ARL libraries, such as Williams (2010) and Detlor and Lewis (2006), others focused on medium libraries, such as Pamela Harpel-Burke (2005). In addition, Bradley P. Tolppanen, Joan Miller, and Martha A. Wooden (2000, 2005) focused on 133 medium-sized libraries. Jones and Leonard (2011) examined 175 small libraries.

Our study belongs in Jones and Leonard's fourth category, as we focus on a variety of design and content issues of medium-sized library home pages. It is the first study focused on analyzing a large population of library home pages for a variety of design attributes since Jones and Leonard (2011), and the first such study of medium-sized libraries since Tolppanen, Miller, and Wooden (2005). Our study breaks new ground by studying an unprecedented number of libraries (313) for a large variety of design and content elements. In addition, by basing our data collection methods and analysis on Jones and Leonard's (2011) study, we can compare our results to theirs, which can help us analyze changes in library Web design over time, as well as identify differences between small and medium-sized libraries. Thus, much of the value of our study lies in applying an established methodology to a new population for 
comparison. Lastly, our study makes a significant contribution by studying the implementations of discovery services by a population of libraries in unprecedented detail.

\section{Methodology}

The purpose of this study was to apply an established Web site evaluation methodology to a new dataset. The advantage of using this methodology instead of surveying librarians on their Web design strategies or conducting usability tests with students was that we were able to review actual Web design implementations among an entire population of libraries. A study of actual practices of an entire population eliminates potential inaccuracies that can arise from partial samples, low response rates, and inaccurate reporting in surveys. The authors specifically sought to determine the frequency of specific design and content elements on medium-sized academic library home pages. Our population was drawn from National Center for Education Statistics data for universities classified as Baccalaureate CollegesGeneral and Master's Colleges and Universities with FTE populations between 3,000 and 9,999 students. This yielded a population of 313 universities. This population was chosen because it is a largely unstudied group of libraries; studies often focus on ARL libraries. Some institutions in the study housed multiple libraries on their campuses. In such cases, we analyzed the home page for the main academic library on campus, not those of more specialized libraries, such as law or music libraries.

The library home pages were viewed and coded from September 11, 2012 to December 30, 2012. Each author was responsible for coding half of the libraries. Having each author code every page was not feasible due to the continual changes in individual Web sites and in overall Web design practice. It would have taken eight or more months for both authors to code every page. During this extended time period, design practices could change, making the study less valuable as a report of design practice at a certain time. Also, the authors' schedules prevented them from coding each page at the same time. If the authors viewed a site’s home page at different times, they might view different versions of the page. The changing nature of Web sites problematize measures of interrater reliability, as changes in the site between author viewings would produce noise in the reliability ratings. In lieu of the above difficulties, to 
promote consistency in coding, the authors first coded ten libraries in common to calibrate coding technique. They also discussed unusual cases in order to promote consistent coding. In addition, once preliminary coding was completed, the data was analyzed for differences in reported data for each author; for example, one author reported many more libraries with links for donations than the other author found in his sample. One author then re-examined all 313 library home pages, focusing on areas where noticeably different frequencies were reported; for example, he re-checked each page specifically for donation links. In this way, the authors minimized error and promoted consistency in coding. The author found very few errors or differences in coding when he went over these pages, and differences he found could be attributable to changes in the pages over time, rather than coding errors.

The coding scheme was drawn almost entirely from the methodology of Jones and Leonard (2011), who drew their methodology from 37 studies and other published sources. To save space, the list from which they drew each element of their coding scheme and methodology is not reproduced in full; rather, modifications to their methodology are noted. Most modifications were made in response to changes in technology or practice that had occurred since Jones and Leonard conducted their study in the spring of 2010. For example, several categories for discovery services were added. All added elements were:

- Discovery Services - We looked for and coded a discovery service, the provider of the service, its branding, the service interface, and whether or not context was provided to describe the service. We adopted Jason Vaughan's (2012) definition of a discovery service as a single, searchable index comprising a large portion of a library's locally-hosted and remotely-licensed content and providing a search interface to explore and locate results within the index.

- Search Options - We added the global library catalog WorldCat as an option.

- Social Media_We coded for the presence of additional social media sites: Google+, Pinterest, LinkedIn, Stumble Upon, Tumblr, and also coded for mobile apps and instant messaging. Given the number of elements we added to the coding scheme and the large number of libraries we studied, we eliminated less important elements from the analysis. For example, we did not record 
information on numbers of drop-down and flyout menus; however, we still counted the total number of links contained within such interactive menus for each site. We also deleted some elements from the coding scheme that we felt were not as central to the study, such as examining the number of links in home page portions that appeared to be part of a general university template and not under the control of the library. We deemed links to be a part of a general university template when they were part of a header or navigation bar appearing on university Web pages beyond the library; since the library did not control these links, it was not a relative element of library home page design. We also did not code for site guides, non-Web exhibits, or the search engine services of Ask.com or Cha-Cha, as Jones and Leonard did not report finding a single instance of these.

When coding, we would indicate that an element was present if it was clearly evident from the home page or could be accessed from pages within one click from the home page. For sites using a common university design template, design elements were recorded if they were present in the portions of the page that the library controlled and were therefore outside of the university-designed template. We did this to focus on elements under the control of the library, not determined by general university Web designers. The only elements recorded regardless of whether they were present in the template or library portions of the page were images, links to the university home page, privacy policies, terms of use, textonly links, mobile links, and links for improved accessibility. To measure how many screens long a page was, the total length of a page, including any necessary scrolling, was measured in centimeters, and then the total was divided by the number of centimeters the browser window displayed without scrolling. Any total less than one screen was counted as one screen.

Pages were viewed using Google Chrome because it was deemed the most common browser during the period of our data collection, according to sources concerning browser market share such as W3Schools (2012). This is worth noting, because browsers can display pages differently. Pages were viewed using a resolution of 1280 x 1024 because W3Schools report that most users operate at a resolution greater than 1024 x 768 . The resolution we used meets the criteria of being greater than $1024 \mathrm{x}$ 
768 without being too large; users operating at high resolutions often will not maximize their browser window and will instead view multiple programs at once.

This study examined a whole population, not a sample of a population, so no inferential statistical tests were needed.

\section{Results}

\section{Design and Navigation Elements}

The mean length of the home page was 1.3 screen lengths, with a standard deviation of .5, as shown in Table 1. Interactive links (links that appear as a result of user interaction, such as drop-down menus, tabbed panels, accordion menus, etc.) were reported on 40.3 percent of library pages.

\section{PLACE TABLE 1 HERE}

Table 2 reports the frequency of layout and navigation features. Overall, 53 percent of home pages clearly used a university template for their design, somewhat lower than the 69.1 percent Jones and Leonard found in smaller libraries. It is worth noting that some sites appeared to use what looked like a standard university template but that was not used by other main pages at the university. Frequently, the page style seemed less polished or contemporary than other pages within the university's site. In these cases, we did not code the site as using a template. It seems possible that in these cases the library was using an older template from which most other pages at the university had shifted; perhaps the library was using technologies incompatible with software used by the university for its current site, or perhaps the library lacked the resources to move the site.

The most common layout for page content was a mixture of columns and sections, employed by

over 41 percent of pages. Columns alone or sections alone were each used by approximately 24 percent of pages. Quick links were used as a navigation feature by almost 20 percent of sites. Site maps or site indexes were used as navigation features in less than 11 percent of home pages. Features that improved 
accessibility, such as text-only links and links to alternate versions of the site, were rare. This does not mean that sites did not focus on accessibility: it is possible some sites were already designed to be accessible without needing an alternate version of the site. Similarly, only 2.6 percent of sites included foreign language links; however, with free and quick Web translation services offered by companies such as Google, the need for including such links may have expired.

\section{PLACE TABLE 2 HERE}

As reported in Table 3, 55.6 percent of library home pages used sidebars for navigation. Sidebar navigation was often used by sites with a university template that had a horizontal top navigation bar for the university’s primary navigation.

\section{PLACE TABLE 3 HERE}

\section{Content Elements}

Five content elements occurred on at least 80 percent of the home pages for libraries at mediumsized academic institutions: a link to the university home page (97.4 percent); library hours (94.6 percent); a link to interlibrary loan (82.7 percent); an “about” section or link (82.1 percent); and portals by subject or links to subject guides (82.1 percent).There were ten other content elements that occurred between 50 percent and 79 percent of the time (see Table 4).

\section{PLACE TABLE 4 HERE}

\section{Search Elements}

Our study coded for a variety of elements involving search functions. As shown in Table 5, almost 40 percent of the home pages in our study contained a discovery service. As previously mentioned, 
we considered a discovery service to be a single, searchable index that both encompassed a large portion of a library's local and licensed content and provided a search interface allowing users to explore and locate results. In order to be coded as a discovery service, the search tool needed to allow for the retrieval of at least electronic journal articles and catalog items, such as books or DVDs. Of the nearly 40 percent of libraries with a discovery service, over two-thirds provided some context to explain the service. In our population, no single discovery service was dominant, but EBSCO Discovery Service (http://www.ebscohost.com/discovery) from EBSCOhost (33.9 percent) and Summon (http://www.serialssolutions.com/summon/) from ProQuest (25 percent) were by far the most common.. In terms of branding the discovery service, we found that the most common strategy was to give the service an original brand name created by the library, with 44.4 percent of libraries using this strategy. An established brand name was used by 29.8 percent, whereas 25.8 percent used no brand name at all. To access the discovery service from the library home page, most libraries chose to place the discovery service as a tab within a multi-tabbed search box (52.4 percent) or position it as its own search box (33.9 percent).

\section{PLACE TABLE 5 HERE}

Overall, 40.9 percent of library home pages contained one or more search functions within a multi-tabbed box. As Table 6 shows, 80.1 percent of libraries had a link leading to a search engine for their OPAC, while 57 percent had a search box on the home page (pages could have both). The second most common link (66.1 percent) and search box (37.1 percent) were for searching titles of e-journals. Links to other libraries (29.3 percent) and WorldCat (29.1 percent) were the two other most common links, while search boxes for the library’s Web site (18.2 percent) and across multiple databases (13.4 percent) were the next most frequently occurring search boxes. While we did not code for it, it should be noted that these multi-tabbed boxes also often contained tabs leading to non-search features, such as 
content or subject guides using an interactive menu interface (e.g., drop-down menu). The authors observed very few sites linking to general Web search engines, such as Yahoo! or Google.

\section{PLACE TABLE 6 HERE}

\section{Multimedia and Social Media Elements}

Most forms of multimedia elements were uncommon on medium-sized library home pages (see Table 7). While images were used on 92.7 percent of pages, the next most commonly occurring element, rotating images, occurred on only 32.3 percent of home pages.

\section{PLACE TABLE 7 HERE}

At least one social media element was located on 87.5 percent of the examined library home pages (see Table 8). Facebook (62.9 percent), chat with a librarian (46 percent), Twitter (39.6 percent), and blogs (33.2 percent) were the most commonly found social media elements for medium-sized libraries.

One Web 2.0 trend that was rarely found in medium-sized libraries was social bookmarking. Carla S. Redden (2010) defines and describes social bookmarking as "the practice of Internet users identifying and labeling Web pages for use later and has become a popular way for individuals to organize and share online resources” (219). She explains that, through an account at a social bookmarking site, users can identify pages worth sharing by tagging them (a process called “social tagging”). Redden argues that social bookmarking and tagging offer potential value to libraries. However, very few library home pages in our population linked to the social bookmarking site Delicious (https://delicious.com/), and sites that use social bookmarking features, such as Digg (http://digg.com/), Flickr, and Pinterest (http://pinterest.com/), also had few links leading to them. While libraries can use proprietary software for 
social bookmarking or can use a branded site without linking to it from the home page, the study found little indication that medium-sized libraries are embracing this Web 2.0 trend.

\section{PLACE TABLE 8 HERE}

\section{Discussion}

The results reveal many differences between home pages of medium-sized libraries in 2012 and the results of previous studies of library Web sites. In many cases, the differences might be due to the passage of time; for example, Jones and Leonard (2011) observed their population in 2010, while Tolppanen et al. observed theirs in 2003. Due to the evolving nature of Web design, even two years might make a noticeable difference in design practices, especially in areas such as social media and multimedia. Some differences between the current study and Tolppanen et al. could be explained by the latter study examining whole sites, while the current study only examined home pages. The differences between the small libraries observed by Jones and Leonard (2011) and the current study also may be due to possible differences in the resources and needs of small libraries compared to medium-sized academic libraries. Barnes, Lescault, and Andonian (2012) found differences in social media usage between the 200 largest and 200 smallest Fortune 500 companies, suggesting that the implementation of Web technologies may be affected by organization size. This may be due to greater resources, but differences in organizational needs between large and small companies could also have an effect. Similarly, when compared with small libraries, the greater size of medium-sized libraries may lead to more complex sites, with more links and a greater need for more complex navigational features, such as multi-tabbed boxes. Likewise, the larger size may not simply provide more resources to devote to maintaining social media accounts, but it also may naturally provide more content to place within social media sites.

While the average screen length found in the current study was identical to the results Jones and Leonard (2011) found in smaller libraries, the mean number of initially visible links in the current study was 56 percent higher than the number of such links found by Jones and Leonard. The increased number 
of links may be the result of the development of additional features over the two years since Jones and Leonard gathered data, and perhaps because the medium-sized libraries have more resources and thus offer more services than smaller libraries. Additionally, it is possible that Web designers of medium-sized libraries are under more pressure from a larger number of stakeholders to include content and must include more links to accommodate these stakeholders. Regardless, this greater number of links likely takes more cognitive work for users to process.

The libraries in the current study contained interactive links, such as drop-down menus, with almost twice the frequency with which Jones and Leonard reported such links: again, this could be because of changes over time or the greater resources of the medium-sized libraries. Oddly, the mean number of interactive links for medium-sized library home pages (for those that contained such links) was the same for both our study and those found by Jones and Leonard within their sample, though their sample had a much higher standard deviation (46.1); this means there was much more variation in the number of interactive links within the home pages they studied. The increase in frequency of interactive links occurring on library home pages may reflect changes to general Web design practices or may be indicative of libraries trying to fit more content into a finite amount of space. For example, drop-down menus may allow libraries to categorize or group links so that they are initially hidden from users, thereby presenting a less cluttered interface.

Multimedia was much more common in medium-sized libraries than the smaller libraries Jones and Leonard observed. This includes images (6.1 percentage points higher), rotating images (23.2 percentage points higher), video tutorials (10.6 percentage points higher), and virtual tours (9.5 percentage points higher). The presence of a mobile link, occurring on 28.4 percent of home pages in our study, was much greater than the incidence of mobile links or apps (14 percent) found by Robin Canuel and Chad Crichton (2011) in Association of Universities and Colleges of Canada (AUCC) libraries. Multimedia and mobile links are both instances in which changes in technology, such as the growth in quantity and variety of mobile devices available to consumers, and differences in population, such as an 
increase in library patrons using mobile devices to access academic and library content, likely had an impact on frequency of implementation.

One area where evolving technology likely had a major impact is in the use of social media and other Web 2.0 technologies. Such technologies were present on 87.5 percent of the sites of medium-sized libraries, a significant increase from the 51.4 percent observed by Jones and Leonard (2011) in small library home pages in 2010. While the same four Web 2.0 technologies were most common in both studies, their order differed, with Facebook surpassing chat in frequency of implementation. This is likely due to both Facebook’s rapid growth in popularity during this time period and the fact that a Facebook page requires far fewer resources than does a chat window. Twitter also surpassed blogs in frequency. This may be because of Twitter's rise in popularity and because entries (tweets) on Twitter can take less effort than blog postings because they are typically shorter than blog postings (although crafting a quality tweet within Twitter's 140-character limit takes skill). The resources allocated to Web 2.0 elements are important, as Chua et al. (2012) found when studying government Web sites that showed the presence of Web 2.0 elements correlated with perceived quality. It seems likely that such a correlation might also exist for libraries.

The authors observed very few sites linking to general Web search engines, such as Yahoo! or Google. This is likely because most students already know of these sites and can access them on their own; Google, for example, has over 86 percent of the search engine market share in the United States (Karma Snack 2013). That said, links to Google Scholar, Google’s search engine for scholarly literature, appeared on 10.9 percent of library home pages. It is feasible that librarians see value in promoting this search service as a way for students to connect the dots between a popular search engine and scholarly materials that will help students in their academic pursuits.

When comparing the current study with Melissa A. Hofmann and Sharon Q. Yang’s study (2012), the difference in the prevalence of discovery services and in the services' market share is unclear. Discovery services were found more frequently in this study's sample (39.6 percent) than were found by Hofmann and Yang, who found such services present in 29 percent of the 260 U.S. and Canadian libraries 
of various sizes that they studied in 2011. For discovery service market share, we found EBSCO Discovery Service and Summon to be by far the most common discovery services, which represents a significant difference from the findings of Hofmann and Yang, who found WorldCat (OCLC; https://www.oclc.org/worldcat.en.html), VuFind (http://vufind.org/), and Summon as the most common services. The differences may be the result of differences in sample populations, differences in definitions of discovery service, or actual changes in market share. However, rapid changes during the early years of the implementation of new technologies should not be surprising.

Web designers can draw from the current study to inform design decisions. A core component of a Web site was defined by Tolppanen et al. (2005) as any component that occurred on at least 50 percent of sites, and they identified 42 such components. Jones and Leonard (2011), applying the same standard to small library home pages, found fourteen core components. In our study of home pages, we found 21 such components. Jones (2012), in a study of government agency home pages, made a further distinction of element frequency, dividing them into widespread (occurring on 75 percent or more of sites in a study) and common (occurring on 50 to 80 percent of sites in a study). Jones argued that widespread elements are occurring frequently enough that designers at sites not including them should strongly consider employing them as well. The assumption is that most designers are competent professionals and that, if 80 percent or more of the designers of home pages in a population have chosen to employ a design element, it likely has value. There were seven items occurring on 80 percent or more of home pages in our sample (in order of decreasing frequency):

1. Link to university

2. Hours

3. Images

4. Link for interlibrary loan

5. “About” link or section

6. Portals by subject or links to subject guides

7. OPAC search link 
These elements were highly prevalent, and medium-sized library Web sites should consider including them if they do not already do so. Meanwhile, the other fourteen elements occurring on 50 percent or more of home pages are as follows (in order of decreasing frequency):

1. Link to library instruction tutorials or guides

2. Link to course reserves

3. News/events/what's new section or link

4. Contact librarian link

5. Contact us (unspecified) link

6. Facebook link

7. Staff directory link

8. Other reference resources (style guides, dictionary) link

9. Help or FAQ link

10. OPAC search box

11. Sidebar navigation within library section (i.e. not within university template)

12. Link for e-books or readers such as Kindle

13. Use of university template

14. Link to library policies

Because these elements also occur on at least half of medium-sized libraries' home pages, those libraries not including such elements may want to consider adding them.

The elements that were least common may also provide some guidance for designers of mediumsized library home pages. The elements occurring on fewer than 2 percent of the 313 medium-sized library home pages in our study are as follows:

1. Links to non-Google Internet search engines

2. Audio links (not podcast)

3. Automatically playing videos

4. Link to discussion forums 
5. Link to interactive instruction schedule

6. Embedded YouTube video

7. Polls

8. User comments

9. Link to Delicious, LinkedIn, Myspace, StumbleUpon, Tumblr

10. Primary layout: Content arranged in four equally divided sections

Designers considering including these elements should weigh their potential merits for their library's specific needs. While common practices may indicate a general value, every library may have specific needs. In addition, some elements may be less common because they are newer and have yet to gain widespread acceptance, despite their value. But in many cases, there may well be good reasons for not including them.

One can combine these results with the similar results Jones and Leonard (2011) found in their study of small academic libraries to develop a bigger picture of elements that are common in small and medium-sized academic libraries. Overall, the two studies collected data from 488 libraries (albeit two years apart from each other). The items that were found on 50 percent or more home pages in both studies were found in a large number of library home pages in data collected only two years apart-it is therefore likely such elements could be useful for inclusion on home pages for libraries of any size. Tolppanen et al. suggested arranging elements on the library Web page so that "high priority items” may be found quickly and easily $(2000,13)$. The authors of this study put forward the following eleven high-priority items, found in 50 percent or more home pages in both studies and listed in order of decreasing frequency at medium-sized libraries:

1. Link to university home page

2. Library hours

3. Images

4. Interlibrary loan link

5. “About” link or section 


\section{Link to search of OPAC}

7. Link to library instruction tutorials or guides

8. Contact librarian link

9. Link to staff directory

10. Sidebar navigation within library section

11. Use of university template

Although our study and the study conducted by Jones and Leonard in 2010 found nearly a dozen core components, the medium-sized libraries still had 50 percent more items that occurred on 50 percent or more pages. There are several possible reasons why medium-sized libraries had more core elements than smaller libraries. Perhaps library home page design practices became more standardized during the two years separating the studies. This could be because of an increase in the pervasiveness of technologies such as e-books, e-readers, and Facebook profiles, especially for organizations. A second reason for the increase in elements occurring on more than 50 percent of pages may be that medium-sized libraries, with their greater resources, are better able to identify and implement optimal trends in design practices. With fewer medium-sized libraries using university templates, designers may have more Web real estate to devote to library-specific content; this could open up possibilities for including content elements on the home page, such as subject guides and reference resources that may have otherwise been relegated to pages deeper within the Web site. The impact that greater resources at medium-sized libraries may have on home page design should not be discounted or minimized. Larger staffs, multifaceted expertise, and more design flexibility may all contribute to the ability of medium-sized libraries to adopt Web design best practices.

Overall, the presence of only 21 (17.8 percent) core components from a list of 118 design elements indicates there is still a great degree of variability in the design of library Web sites. As Geoffrey Little (2012) observed, librarians lack clear and accepted professional standards for Web sites and digital services. This suggests that librarians and Web designers can still take steps toward improving the navigability and usability of their pages. In an age in which library resources are often found through 
online catalogs, it is surprising that fewer than 100 percent of libraries lacked a link to their OPAC. Since the library Web site is only one avenue (others being course management and library guides) through which users may access library materials, though, it is possible libraries link to their OPACs through other means.

The increase in the mean for initially-visible links from Jones and Leonard's study in 2010 to this study indicates that libraries may need to question whether they are moving in the direction of improved site usability. Web designers must be judicious in their use of links so as not to overwhelm users; as Chen et al. (2011) noted, greater numbers of links on Web pages can lead to increased user disorientation when navigating. The use of initially invisible links is also an important consideration as more and more library patrons use mobile devices to access library Web content: interactive links may render differently on various mobile devices, so libraries should consider usability testing their Web sites on mobile devices prior to adding a large number of interactive links to their Web sites. In addition, although this study did not specifically evaluate the terminology used on library Web sites, designers and librarians must also be thoughtful in their vocabulary selections. Library jargon, such as federated searching, may be unclear to some users, so libraries must take steps to use clear language on their Web sites.

Finally, there are a lot of design elements that many libraries do not use. Those libraries may be able to enhance their pages by implementing currently under-used content elements. Site indexes and site maps may help users better navigate library Web pages, and video tutorials or other multimedia elements could enable libraries to better engage with and educate their users. Multimedia, in particular, emerged as one area in which libraries can seek improvement. Chen et al. (2011) found when studying general Web design that multimedia elements tended to increase user satisfaction with sites. Following Chen et al.'s discovery, then, libraries might improve user satisfaction by implementing more multimedia functions. Another related area offering room for improvement is mobile links and apps. While the library home pages studied contained few links to mobile sites and very few links to mobile apps, mobile access will become increasingly important in the future. Canuel and Crichton (2011) argue that the increasing ubiquity of smartphones in society at large (and students in particular) offers great potential for academic 
libraries. Fatt Cheong Choy argues more strongly for a mobile presence for libraries, stating that, "If users are using mobile devices as the de-facto interface in their transactions with the electronic world, libraries must have a presence to take advantage of this heightened convenience that is in the hands of our users” (67). Given that less than one-third of the libraries we accessed indicated that they offered mobile options, this is an area libraries need to further develop. Moreover, even if the libraries did offer mobile access without advertising it on their home pages, the lack of alerts or announcements on the home pages indicates a need to do a better job of promoting mobile access to students.

Ultimately, effective library Web sites require more than simply the inclusion of certain elements. For example, Amy Fry and Linda Rich (2011) found that students can have difficulty choosing which databases to use for a search. Students they observed often did not properly use subject guides and database lists (if they used them at all). Many students simply replied on whatever branded databases they had been instructed to use as freshmen. Fry and Rich argued that improved list design and instruction are needed to promote proper resource usage from students. Libraries can put these recommendations into practice by carefully reviewing both the content elements and organizational methods used on their Web pages. Paying close attention to where and how elements are placed will allow libraries to show their users how to successfully navigate the library Web site.

\section{Conclusion}

As research becomes increasingly dependent on electronic resources, academic library home pages will become correspondingly central to the practice of academic research. Originally begun as a supplement to the academic library’s physical structure and services, library Web sites have become a vital part of the library’s framework as they present a library's services and resources to user communities. As the front door to the library's online presence, the home page in particular deserves proper attention to help patrons as they conduct their research. Many patrons are students with less experience with the library's online resources, so careful attention to design is needed in order to best promote access to the online collection. Usability studies take time and money, and given the large 
number of potential designs, it is prohibitive to study all of the various design options and services that a library Web site could offer. Yong-Mi Kim (2011) noted that libraries often lack sufficient training and resources to support the design process. In addition, Kim found that academic library Web designers often review other library Web sites when developing their own designs, because the design of other libraries exerted a mimetic force. While Kim saw this activity largely in terms of attempting to secure legitimacy for the decisions of designers, we think studying the designs of other libraries can improve site designs, because designers and librarians can use a wisdom-of-crowds approach to aid in their design processes.

The fluid nature of Web design means there is opportunity to replicate this study in the future in order to identify similarities and differences in design choices, particularly in regard to emerging technologies and user engagement services. Because this is one of the first studies that incorporated discovery service implementation on a population of library home pages, it will be beneficial to evaluate any changes in the adoption of these next-generation library search tools, including changes in libraries’ choices. The library home page is a critical portal to library resources, but another avenue for exploration is alternative portals, such as course management systems and Google sites. Analysis of the design elements and perhaps even vocabulary used on other learning platforms may yield useful results and tips for library Web site design.

Medium-sized libraries are sandwiched between small and large institutions and must balance higher student counts with resource limitations. A comparison of the design elements on these library home pages revealed several core elements that libraries of any size should consider implementing on their Web sites. Furthermore, medium-sized libraries may be in a distinctive position to experiment with their site design, because they may have greater resources to devote to their Web pages than small libraries but not as many stakeholders as large libraries. As such, analysis of this population may unearth widespread design standards and potential trends. Desired or not, libraries today compete with the simplistic and easy-to-use interfaces of popular Web search engines. In order to connect users with the resources and services they need in order to achieve collegiate success, libraries should continue to explore intuitive and appealing ways to present their content and draw users to the library Web site. 


\section{References}

Aharony, Noa. 2012. “An Analysis of American Academic Libraries’ Websites: 2000-2010.” The Electronic Library 30 (6): 764-776. doi:10.1108/02640471211282091.

Barnes, Nora Ganim, Ava M. Lescault, and Justina Andonian. 2012. “Social Media Surge by the 2012 Fortune 500: Increase Use of Blogs, Facebook, Twitter and More.” Center for Marketing Research. Accessed January 15, 2013. http://www.umassd.edu/cmr/socialmedia/2012fortune500/.

Blummer, Barbara A. 2007. “A Literature Review of Academic Library Web Page Studies.” Journal of Web Librarianship 1 (1): 45-64. doi:10.1300/j502v01n01_04.

Canuel, Robin, and Chad Crichton. 2011. “Canadian Academic Libraries and the Mobile Web.” New Library World 112 (3): 107-120. doi:10.1108/03074801111117014.

Chen, Jengshung Victor, Chinho Lin, David C. Yen, and Kyaw-Phyo Linn. 2011. "The Interaction Effects of Familiarity, Breadth and Media Usage on Web Browsing Experience.” Computers in Human Behavior 27 (6): 2141-2152. doi:10.1016/j.chb.2011.06.008.

Choy, Fatt Cheong. 2011. “From Library Stacks to Library-in-a-Pocket: Will Users Be Around?” Library Management 32 (1): 62-72. doi:10.1108/01435121111102584.

Chua, Alton Y.K., Dion H. Goh, and Rebecca P. Ang. 2012. "Web 2.0 Applications in Government Web Sites: Prevalence, Use and Correlations with Perceived Web Site Quality.” Online Information Review 36 (2): 175-195. doi:10.1108/14684521211229020.

Detlor, Brian, and Vivian Lewis. 2006. “Academic Library Web Sites: Current Practice and Future Directions.” Journal of Academic Librarianship 32 (3): 251-258. doi:10.1016/j.acalib.2006.02.007. Emanuel, Jennifer. 2011. “Usability of the VuFind Next-Generation Online Catalog.” Information Technology and Libraries 30 (1): 44-52. doi:10.6017/ital.v30i1.3044. 
Fry, Amy, and Linda Rich. 2011. “Usability Testing for E-Resource Discovery: How Students Find and Choose E-Resources Using Library Web Sites.” The Journal of Academic Librarianship 37 (5): 386401. doi:10.1016/j.acalib.2011.06.003.

Ganster, Ligaya, and Bridget Schumacher. 2009. “Expanding Beyond our Library Walls: Building an Active Online Community through Facebook.” Journal of Web Librarianship 3 (2): 111-128. doi:10.1080/19322900902820929.

Harpel-Burke, Pamela. 2005. “Library Homepage Design at Medium-sized Universities: A Comparison to Commercial Homepages via Nielsen and Tahir.” OCLC Systems and Services 21 (3): 193-208. doi:10.1108/10650750510612399.

Hofmann, Melissa A., and Sharon Q. Yang. 2012. “'Discovering’ What's Changed: A Revisit of the OPACs of 260 Academic Libraries.” Library Hi Tech 30 (2): 253-274. doi:10.1108/07378831211239942.

Jones, Scott L. 2012. “A Census of State Portal and Agency Homepage Design in the United States.” International Journal of Electronic Government Research 8 (2): 32-56. doi:10.4018/jegr.2012040102.

Jones, Scott L., and Dianna DeGrow. 2011. “Fortune 500 Homepage Design Trends.” IEEE Transactions on Professional Communication 54 (1): 18-30. doi:10.1109/TPC.2010.2044621.

Jones, Scott, and Kirsten Leonard. 2011. “Library Homepage Design at Smaller Bachelor of Arts Institutions.” Journal of Web Librarianship 5 (1): 24-45. doi: 10.1080/19322909.2011.546216.

Karma Snack. 2013. “Jan 2013 - Updated // Search Engine Market Share.” KarmaSnack.com. Accessed January 6, 2013. http://www.karmasnack.com/about/search-engine-market-share/.

Kim, Yong-Mi. 2011. “Factors Affecting University Library Website Design.” Information Technology \& Libraries 30 (3): 99-107. doi:10.6017/ital.v30i3.1768.

King, David L. 1998. “Library Home Page Design: A Comparison of Page Layout for Front-Ends to ARL Library Web Sites.” College \& Research Libraries 59 (5): 457-464. http://crl.acrl.org/content/59/5/457.full.pdf. 
Kneip, Jason. (2007). “Library Webmasters in Medium-Sized Academic Libraries.” Journal of Web Librarianship 1 (3): 3-23. doi:10.1300/J502v01n03_02.

Little, Geoffrey. 2012. "Where Are You Going, Where Have You Been? The Evolution of the Academic Library Web Site.” The Journal of Academic Librarianship 38 (2): 123-125. doi: 10.1016/j.acalib.2012.02.005.

Majors, Rice. 2012 “Comparative User Experiences of Next-Generation Catalogue Interfaces.” Library Trends 61 (1): 186-207. doi:10.1353/lib.2012.0029.

Moore, Kate B., and Courtney Greene. 2012. “The Search for a New OPAC: Selecting an Open Source Discovery Layer.” Serials Review 38 (1): 24-30. doi:10.1016/j.serrev.2011.12.005.

Nielsen, Jakob, and Marie Tahir. 2001. Homepage usability. Indianapolis, IN: New Riders.

Redden, Carla S. 2010. “Social Bookmarking in Academic Libraries: Trends and Applications.” The Journal of Academic Librarianship 36 (3): 219-227. doi:10.1016/j.acalib.2010.03.004.

Rempel, Hannah G. 2010. "Services for Graduate Students: A Review of Academic Library Web Sites.” Journal of Web Librarianship 4 (1): 19-35. doi:10.1080/19322900903492983.

Stover, Mark, and Steven D. Zink. 1996. “World Wide Web Home Page Design: Patterns and Anomalies of Higher Education Library Home Pages.” Reference Services Review 24 (3): 7-20. doi:10.1108/eb049284.

Swanson, Troy A., and Jeremy Green. 2011. "Why We Are Not Google: Lessons from a Library Web Site Usability Study.” The Journal of Academic Librarianship 37 (3): 222-229. doi:10.1016/j.acalib.2011.02.014.

Tidal, Junior. 2012. “Creating a User-Centered Library Homepage: A Case Study.” OCLC Systems \& Services 28 (2): 90-100. doi:10.1108/10650751211236631.

Tolppanen, Bradley P., Joan Miller, and Martha A. Wooden. 2000. “An Examination of Library World Wide Web Sites at Medium-sized Universities.” Internet Reference Services Quarterly 5 (2): 5-17. doi:10.1300/J136v05n02_02. 
----. 2005. “Library World Wide Web Sites at Medium-sized Universities: A Re-examination.” Internet Reference Services Quarterly 10 (2): 7-18. doi:10.1300/j136v10n02_02.

Vaughan, Jason. 2012. “Investigations into Library Web-scale Discovery Services.” Information Technology \& Libraries 31 (1): 32-82. doi:10.6017/ital.v31i1.1916.

W3Schools. 2012. “Brower Statistics.” W3Schools.com. Accessed December 30, 2012. http://www.w3schools.com/browsers/browsers_stats.asp.

Williams, Sarah C. 2010. "Federated Search and the Library Web Site: A Study of Association of Research Libraries Member Web Sites.” Journal of Web Librarianship 4 (1): 3-18. doi:10.1080/19322900903496273. 